\title{
UNIVERSIDADE E NOVOS MODOS DE PRODUÇÃO, CIRCULAÇÃO E APLICAÇÃO DO CONHECIMENTO
}

\author{
José Dias SobrinHo*
}

Recebido: 3 jun. 2014

Aprovado: 31 jul. 2014

*Programa de Pós-graduação em Educação da Universidade de Sorocaba. Sorocaba, SP, Brasil. E-mail: jose.sobrinho@prof.uniso.br

Resumo: Nunca antes na história o desenvolvimento da sociedade mundial dependera tanto do conhecimento e da informação. Portanto, é plausível reconhecer a enorme importância da universidade atual no mundo todo. Ela sofre e alimenta algumas das graves contradições e dilemas deste período de crises de sentidos e de espetaculares transformações. Como locus e ator, acolhe e fomenta as contradições e o hibridismo de modos distintos de produção, circulação e usos do conhecimento: o tradicional "modo 1", fechado e monodisciplinar, e o novo "modo 2", aberto, transdisciplinar, de uso intensivo e extensivo dos meios informáticos. A produção de conhecimentos cresce exponencialmente com a globalização da conectividade. A questão não é apenas formal e quantitativa. Discutir a universidade e os processos de produção e utilização dos conhecimentos impõe refletir sobre os seus significados para a existência concreta dos homens e mulheres na construção da vida pessoal, social e para a humanidade em geral. Por inserir-se na sociedade global, a universidade valoriza prevalentemente o "capitalismo acadêmico" próprio de uma "economia do conhecimento". Mas a universidade atual também tem incomensuráveis possibilidades de contribuir para os processos de construção de uma "sociedade democrática do conhecimento" e de recuperar sua missão histórica no processo civilizatório.

Palavras-chave: Universidade. Conhecimento. Modos de produção de conhecimentos. "Capitalismo acadêmico". Sociedade democrática do conhecimento.

\section{UNIVERSITY AND NEWS MODES OF PRODUCTION, CIRCULATION AND APPLICATION OF KNOWLEDGE}

Abstract: Never before has the development of the world society depended so much on knowledge and information. Thus, it is plausible to recognize the enormous importance of universities throughout the world. The university feeds and is fed by some of the grave contradictions and dilemmas of this period of crisis of meanings and of spectacular changes. As locus and actor, it embraces and stimulates the contradictions and hybridism of different modes of production, circulation and uses of knowledge: the traditional "mode 1", closed and disciplinary, and the new "mode 2", open, transdisciplinary, intensive and extensive on the uses it makes of information technologies. Knowledge production increases exponentially with the globalization of connectivity. The question is not only formal and quantitative. To discuss the role of universities and the process of knowledge production it is necessary to ponder on their meanings to the concrete existence of men and women on shaping their personal and social lives. Being a part of global society, universities tend to value "academic capitalism", typical of "knowledge economies". But they also hold the potential to contribute to the processes of building "democratic knowledge societies" and to recover their historic mission of promoting a civilizatory process.

Key words: University. Knowledge. Modes of knowledge production. “Academic capitalism”. Democratic knowledge societies. 


\section{INTRODUÇÃO: EDUCAÇÃO SUPERIOR E GLOBALIZAÇÃO}

Estes são tempos de desassossego, perplexidades e perdas das referências valorativas da vida. "Tempos fraturados", conforme título de um livro de Hobsbawum, "uma época da história que perdeu o rumo e que" - continua esse renomado historiador - "nos primeiros anos do novo milênio, com mais perplexidade do que lembro ter visto numa já longa vida, aguarda, desgovernada e desorientada, um futuro irreconhecível" (2013, p. 9-10). O sujeito vive em estado de incertezas sobre sua vida e sobre os destinos do mundo no presente e no futuro que lhe caberá viver. A insegurança, que antes rondava a esfera privada do indivíduo em sua luta por sobrevivência, agora também contamina as sociedades em todos os seus âmbitos, dos mais restritos e íntimos aos mais amplos e públicos. Novos e velhos problemas, atuais e antigos desafios socioprofissionais se acumulam e se transformam rapidamente em razão das mudanças no mundo do trabalho, nos modos de vida individuais, nas conformações societárias locais e suas relações com as outras nos espaços planetários e - tema a ser privilegiado neste texto - nas transformações nos modos de produção, distribuição e consumo dos conhecimentos em contextos de grande volatilidade.

O mercado, em proveito próprio, procura por todos os meios assumir a prerrogativa de organizar a sociedade. $\mathrm{O}$ valor dinheiro, isto é, o preço, a rentabilidade, em grande parte substitui os valores e princípios da moralidade e da democracia. O sistema econômico dominante prometeu o progresso e a salvação da humanidade, mas, ao contrário, está produzindo a destruição dos sonhos de liberdade, solidariedade e justiça social. Mediante os processos de individualização, "torna-se poroso o conglomerado social, a sociedade perde consciência coletiva e sua capacidade de negociação política. A busca de respostas políticas às grandes questões do futuro fica sem sujeito e sem lugar" (BECK, 2008, p. 25).

São de diversa natureza as rápidas e profundas transformações que hoje ocorrem em todas as dimensões da vida humana: na economia, na política, na cultura, no mundo do trabalho, nas relações entre produtores e consumidores, na ecologia, na sociedade civil. Estados nacionais debilitados e interdependentes estabelecem relações simbióticas com poderosos atores transnacionais. Esse é o quadro de sustentação em que transita a internacionalização do capital. A sociedade de economia global, movida pelas grandes empresas comerciais transnacionais e assegurada financeira, política e ideologicamente pelos organismos multilaterais, é motorizada pelos conhecimentos utilitários potencializados pelas onipresentes tecnologias informacionais. Esses são aspectos 
constituintes das complexas transformações geopolíticas, geoeconômicas e civilizacionais que caracterizam o mundo contemporâneo.

Todas essas mudanças afetam de diferentes maneiras as sociedades, os Estados, as forças produtivas, os movimentos sociais e as formas de vida dos indivíduos nas trocas simbólicas que se dão nas diversas circunstâncias das práticas cotidianas, nas relações com o mundo de fronteiras físicas e temporais dissolvidas. Ninguém está imune às grandes metamorfoses que se produzem em todas as esferas, em decorrência, principalmente, das imposições da economia neoliberal, cimentada pelo informacionalismo global. "Inclusive os marginalizados vivem nos e dos desejos da sociedade mundial e permanecem ligados à circulação simbólica da indústria cultural global” (BECK, 2008, p. 101).

A racionalidade da construção da vida pública vem escapando do domínio dos sujeitos. Rompem-se as teias, contraditórias, das relações sociais. Determinada pelas diretrizes economicistas, a sociedade se transforma em espaço de intercâmbios de natureza mercadológica. Esgarçada a associação entre política, cultura e economia, ostenta-se soberano o mercado global. No vazio do enfraquecimento do Estado, a economia neoliberal global, por meio dos núcleos financeiros interligados em redes telecomunicativas, avança sua dominação sobre a política, a cultura e a sociedade nacionais e determina os modelos e papéis da educação e do conhecimento em função do aumento da capacidade dos países e dos indivíduos para a competitividade e a inserção transnacional.

Conforma-se assim o cenário contraditório de concorrências, assimetrias culturais, exclusões sociais, globalização da violência, aumento de massas de miséria e, também, de ilhas de prosperidade, crescimento da capacidade de consumo e impressionantes avanços científicos e tecnológicos que trazem importantes benefícios, porém, só a uma parcela da população mundial. A globalização penetra em todos os espaços mundiais, mas não são nada homogêneos e igualitários seus impactos sobre os aproximadamente 7.000.000.000 de indivíduos deste planeta.

Nada disso é alheio à educação e ao conhecimento. As crises econômicas, políticas e, sobretudo, de sentidos e valores que assolam os Estados, as comunidades, o mundo do trabalho e o sujeito atingem frontalmente a educação e a cultura. De modo especial, a educação superior é profundamente afetada, em razão da responsabilidade que lhe é atribuída de produzir, fomentar e disseminar os conhecimentos, as técnicas e habilidades úteis ao desenvolvimento das condições de possibilidade da economia global. Essa economia globalmente imposta se nutre da instrumentalidade do conhecimento e das competências 
técnicas a ele associadas e impõe à educação superior a incumbência de fortalecer o sistema produtivo e potencializar as riquezas econômicas.

A centralidade da educação superior nas agendas de consolidação e expansão da economia global e neoliberal, de base tecnológica e informacional, é atravessada de crises, conflitos e contradições. Muito dessa problemática se deve certamente ao contexto mais amplo. São crises, conflitos e contradições do mundo globalizado destes tempos. Mas, em seu campo próprio, as instituições de educação superior, em graus muito diversos, não conseguem corresponder à complexidade das demandas a que se submetem. De modo especial, não conseguem acompanhar as mudanças nos novos modos de produção e de distribuição de conhecimentos em contextos de uma voraz explosão epistêmica em diversas áreas, muito menos resolvem os conflitos ideológicos e políticos dos diferentes grupos de interesse que constituem as múltiplas contradições das formações sociais.

Mas se há crises de diferentes dimensões, também há formidáveis oportunidades de avanços na perspectiva da construção de uma sociedade democrática nestes que são os tempos do conhecimento. Jamais em outro momento da história houve tantas possibilidades de produzir, ampliar e divulgar tantos e tão variados conhecimentos. Não se trata apenas de uma questão quantitativa e de forma. O que mais importa é refletir sobre os significados do conhecimento na construção da sociedade humana.

As transições entre modos distintos de produção e uso dos conhecimentos afetam as estruturas universitárias e vice-versa. O que mais interessa trazer ao debate é a concepção última do que seria hoje a educação, de modo geral, e, em particular, a universidade. Em termos mais claros, o que aqui prioritariamente se coloca em questão são as novas finalidades que hoje impendem à educação superior e que esta se impõe, tendo em vista sua função essencial de formadora de profissionais e cidadãos e a importância central do conhecimento para o desenvolvimento econômico e social. Capacitação profissional e fortalecimento da economia como fins em si mesmos ou fazendo parte da formação integral do cidadão e da construção da sociedade justa e democrática?

Essa temática anima as reflexões que se seguem.

\section{UNIVERSIDADE NA ECONOMIA DO CONHECIMENTO}

Não há hoje nenhum setor de atividades profissionais que possa se considerar imune às discrepâncias entre educação e trabalho e escape do fantasma do desemprego e dos riscos do subemprego. Ulrich Beck atribui a essa reali- 
dade de educação sem emprego a metáfora de "estação-fantasma". Os trens já não circulam conforme previsto, as filas de espera se acumulam e bilhetes são vendidos para trens já lotados e que não seguirão para os destinos indicados. De todo modo, é imprescindível ter o bilhete, mesmo que não se vá a lugar nenhum. É imprescindível ter mais educação, mesmo que a escola não seja capaz de prover qualificação profissional adequada e precárias sejam as estruturas e possibilidades de empregos. Aí se instaura certa irracionalidade: os jovens descreem da educação como instituição garantidora de trabalho futuro, os professores estão defasados em relação às novas realidades do mundo e perdem a autoridade, os currículos, conteúdos e práticas pedagógicas se tornam irreais. $\mathrm{O}$ contexto educacional se modifica, mas os agentes não sabem muito bem o que fazer. Diz Beck (2010, p. 219):

O sentido fundamental da educação profissionalizante é ameaçado ou destruído pela incidência de rupturas no mercado de trabalho. O futuro profissional almejado mas (ainda) inexistente, ou seja, uma 'variável irreal', promove uma alteração radical da situação no sistema educacional.

Aqui cabe aflorar uma discussão a respeito de dois fenômenos distintos e que podem jogar luz nos movimentos que produzem fragmentações e contradições na educação superior. Trata-se do intento de compreender um pouco mais dois conceitos em moda: sociedade do conhecimento e economia do conhecimento, ou sociedade de economia do conhecimento. Ou sociedades do conhecimento, no plural, como Didriksson prefere. Esses termos não se equivalem e tampouco são neutros. As sociedades do conhecimento são ainda uma utopia, algo a ser construído. As economias do conhecimento são uma realidade, ao menos para parte importante dos países industrialmente avançados, que não poderiam existir sem a redefinição dos papéis da universidade, pois dependem centralmente da produção científica e tecnológica (DIDRIKSSON, 2010, p. 84-96).

Cabe, então, fazer um reparo ao artifício ideológico que esconde uma armadilha na expressão "sociedade de economia global". Essa expressão acolhe naturalmente dois conceitos, "sociedade" e "economia global", cujos valores dificilmente se coadunam na conjuntura histórica contemporânea. A atual economia global tem como característica essencial o livre funcionamento do mercado transnacional mundial, em grande parte sob o regime da digitalização.

Nesse capitalismo global destituído de uma autoridade suficientemente forte para além dos espaços estatais nacionais, não há lugar para uma sociedade 
ou uma comunidade global. Prevalecem os interesses egoístas e rompem-se os valores morais que asseguram a pertença do indivíduo a uma comunidade ou a uma sociedade. O indivíduo é o elemento impulsionador da economia global e neoliberal, e é essa economia, segundo seus interesses e suas doutrinas, quem organiza a sociedade, não de cidadãos, mas, prevalentemente, de consumidores.

A economia do conhecimento está amplamente enraizada no mundo contemporâneo e constitui o cerne da globalização dos mercados. Ela valoriza predominantemente os conhecimentos que apresentam critérios de utilidade e aplicabilidade às organizações mercantis. Esses conhecimentos, notavelmente impulsionados pelos avanços das tecnologias que movem o capitalismo informacional, são o motor do modelo de progresso vigente. A título de agregar riquezas às grandes corporações e o lucro sem limites às elites proprietárias, esse modelo de progresso e desenvolvimento vem aprofundando desigualdades sociais, guerras, destruição do meio ambiente, crise de valores e incertezas em amplos setores da vida humana, inclusive na própria economia, foco central de sua referencialidade.

$\mathrm{Na}$ economia global, as crises também tendem a ser globais, embora se reconheçam diferenças regionais de intensidade e duração que ocorrem em função das realidades específicas e das respostas de cada país. Mas, mesmo que mais graves em alguns países, as crises econômicas e de valores, de um ou de outro modo, afetam toda a população mundial.

Diferentemente das práticas acadêmicas do passado, o mundo da ciência agora busca tornar-se bastante visível às organizações econômicas, aos decisores políticos, aos operadores dos sistemas de avaliação e financiamento e ao público em geral. Gente da área de produção de conhecimentos a isso chama de responsabilidade social da ciência, que assim estaria se fortalecendo. Esse fenômeno altera as práticas científicas, seu modo de produção, seus objetivos, formas de distribuição e usos.

Mais que o valor público e geral, tende a prevalecer o interesse privado e particular; mais que a criatividade e a reflexão sobre teorias, o foco mais corrente é sobre a resolução de problemas concretos (ZIMAN, 2002, p. 109 apud BUCCHI, 2010, p. 164). Ciência e tecnologia estreitam suas relações com as esferas dos negócios. Investimentos privados competem, nos países ricos, com os financiamentos públicos. São cada vez mais frequentes as relações simbióticas entre universidades, centros de pesquisa, spin-offs e empresas, notadamente as multinacionais. O interesse de desfrutar os benefícios comerciais, em muitos casos, leva ao paradoxo da preservação do sigilo ou, por outro lado, da ampla divulgação das descobertas e avanços científicos. 
Excetuados os casos de sigilo e de direitos autorais, a ciência consolidou um vasto aparato de publicação, conceitos, normas, linguagens e, pode-se acrescentar, uma gramática própria: revistas especializadas devidamente classificadas e com garantia de qualidade, peer review, instituições e mecanismos de contabilização de trabalhos e citações, base de dados, fator de impacto, reputação, prêmios, cessão de direitos, rankings etc. As grandes universidades e os mais renomados centros de pesquisa situados nos países ricos se fortalecem ainda mais como produtores de ciência por meio da criação de redes de colaborações internacionais. As instituições que não se abrem aos contextos cooperativos mundiais tendem a aumentar ainda mais sua escassa significação no cenário global da produção de conhecimentos. Dois tipos de universidades vão se distinguindo: as mais importantes no cenário global são as que mantêm estruturas de colaboração internacional, enquanto mais e mais se fragilizam aquelas que se fecham em seus circuitos internos.

Desmancham-se as fronteiras entre a virtualidade e a realidade. Já se consegue, em muitos casos, acompanhar algumas práticas e produtos científicos quase em tempo real. Alguns pesquisadores disponibilizam a seus colegas, por meios eletrônicos, os seus trabalhos na forma de pré-print e discussões informais.

Um outro fenômeno se faz corrente: alguns aspectos da ciência são divulgados frequentemente pelos meios de comunicação a públicos que normalmente não teriam capacidade de entendê-la. O interesse em receber a atenção da população não pertencente à comunidade científica provocou o desenvolvimento do jornalismo científico e a criação de estruturas de relações públicas e de divulgação da ciência e tecnologia nas universidades e outras instituições de pesquisa. Uma busca no Google pode oferecer a qualquer indivíduo um conjunto de informações sobre algum tema científico, que no passado teria que passar por uma longa cadeia até chegar, quando chegava, ao público em geral.

A proliferação da informação científica para grandes públicos por meio da media introduz uma preocupação importante a respeito das questões dos créditos, da fonte, da transparência, da independência e da capacidade crítica. Segundo pesquisa realizada em jornais nacionais alemães, " $80 \%$ dos artigos sobre questões científicas se basearam em uma única fonte e menos de um terço a menciona explicitamente" (BUCCHI, 2010, p. 174).

Um outro problema diz respeito ao momento da divulgação pelos meios de comunicação, em geral quando ainda há muita incerteza, e sem esperar a estabilização das controvérsias entre os cientistas. Em uma rápida vista de olhos em programas disponibilizados na web se pode constatar que a complexidade 
de um largo processo de pesquisas, filtros, discussões, comprovações e artigos especializados acaba reduzida a poucas palavras e informações superficiais.

A exposição midiática da ciência, sem os necessários filtros científicos, técnicos e éticos, pode acabar servindo a poderosos grupos econômicos, à ressonância pública de certos produtos, ao prestígio social de pesquisadores e à supervalorização de instituições. Negócios, prêmios internacionais de alta reputação e valor econômico, financiamentos, influência política, rankings etc. guardam relações com a exposição midiática da ciência e da tecnologia. Como a ciência e a tecnologia cada vez mais estão aderentes aos contextos de aplicação e envolvidas em interesses, torna-se importante a exposição midiática. Mas não é só isso. Grandes corporações têm seus próprios laboratórios de pesquisa, o que lhes garante a contratação dos mais reputados pesquisadores e mais eficaz controle do sigilo, da produtividade e da pertinência mercadológica.

O novo paradigma imposto pela economia do conhecimento concita a educação superior a transformar-se radicalmente, sob o império do mercado, como se isso fosse uma necessidade inexorável da competitividade no capitalismo globalizado. O conhecimento efetivo na ação é considerado o principal ativo na economia globalizada de informação e de mercado, deixando em segundo plano os produtos materiais. Numa sociedade de emprego precário, o capital intelectual é o mais importante meio de acesso ao trabalho e à riqueza. Os processos relativos ao conhecimento de valor econômico crescentemente se externalizam. As empresas se reestruturam com o objetivo de se adequarem à digitalização e criam equipes polivalentes funcionais (ROIG IBAÑEZ, 2006, p. 234-237).

Os meios infomacionais propiciam uma notável deslocalização da produção de conhecimentos. A universidade e outras instituições oficiais dividem agora com outros espaços sociais e particulares a produção, a distribuição e a aplicação do conhecimento. As exigências de contínua atualização da qualificação profissional se impõem aos docentes e pesquisadores universitários e a seus egressos, e, paralelamente ou em continuação, impulsionam ações intraempresariais de capacitação de acordo com as necessidades momentâneas das empresas, da manutenção da empregabilidade dos trabalhadores e a evolução das formas e diferentes situações de trabalho.

Os sistemas oficiais de educação buscam adaptar-se à nova ordem/desordem econômica e suas constantes mudanças, diversificam a oferta, a duração e a organização curricular de novos cursos e direcionam suas práticas didático-pedagógicas para a qualificação e requalificação de competências e habilidades laborais. 
Como tendência geral, a universidade, está abdicando, ao menos em parte, de sua autorreferencialidade, de sua autonomia, de seu modo de organização e segmentação disciplinar e de sua postura elitista e está sendo concitada a promover mudanças nas suas estruturas e em suas finalidades. A crescente divisão do trabalho e das respectivas competências profissionais influencia, no plano interno, a tendência à diversificação de disciplinas e à interdisciplinaridade, ao surgimento de diferentes tipos de cursos e novos modelos de ensino. A diversificação e a flexibilização de currículos e de modelos institucionais estão estreitamente relacionados com o princípio da liberdade da escolha do cliente, tão reverenciado pelo neoliberalismo. A importância de aumentar a diversificação e a flexibilidade também é uma retórica que esconde a perda da capacidade reflexiva e crítica e as estratégias de horizontes mais amplos e duradouros das instituições educativas.

$\mathrm{Na}$ esteira da economia do conhecimento tendem a prosperar uma mercantilização massiva das atividades educacionais e das instituições privadas, as lógicas empresariais na gestão, na organização dos processos de produção, distribuição e transferência de conhecimentos e nos sentidos da formação. Se a referência central é o lucro, então, os conhecimentos são entendidos mais como propriedades privadas e, portanto, bens comercializáveis, que fundamentos da vida social e, coerentemente, a formação se identifica mais com a capacitação técnica e profissional que com o desenvolvimento integral dos indivíduos, com a equidade e o fortalecimento da cidadania. Nesse modelo econômico, o conhecimento de função utilitarista é apropriado privadamente e se apresenta como um dos mais robustos instrumentos da competitividade individual e de instauração da rivalidade no meio social.

\section{“CAPITALISMO ACADÊMICO” E “UNIVERSIDADE EMPREENDEDORA"}

Slaughter e Leslie cunharam uma expressão bastante apropriada e amplamente reconhecida do fenômeno que vem impactando significativamente as instituições de educação superior: "capitalismo acadêmico" (SLAUGHTER; LESLIE, 1997). Tomando por base estudos de instituições dos Estados Unidos, Grã-Bretanha, Austrália e Canadá, consideram que, apesar de diferenças ente suas culturas políticas, esses países desenvolveram políticas semelhantes em questões em que a educação superior se relaciona com a economia pós-industrial. Afirmam: 
Políticas de educação terciária em todos os países aproximaram-se de ciências e tecnologias que enfatizassem o capitalismo acadêmico, às custas da pesquisa básica ou fundamental, em direção a políticas curriculares que concentravam recursos na ciência e tecnologia e em campos próximos ao mercado [...], objetivando um custo governamental menor por estudante e políticas educacionais que reduzissem a autonomia das instituições acadêmicas e do corpo docente. (SLAUGHTER; LESLIE, 1997, p. 55 apud MORROW; TORRES, 2004, p. 37-38).

A teoria do capitalismo acadêmico denuncia a utilização de recursos públicos por parte de atores acadêmicos para o benefício privado da nova economia. Nas alianças universidades-empresas, se criam redes que diluem as fronteiras entre o público e o privado, especialmente mediante os investimentos em pesquisas e serviços que rendem benefícios econômicos para grupos de atores acadêmicos, ainda que em detrimento da liberdade de pensamento, e são estratégicos para o aumento da competitividade de organizações do mercado.

O ensino, a construção de aprendizagens, a expertise acadêmica, a transferência de conhecimentos e os resultados dos processos de inovação realizados pelos atores aderentes ao capitalismo acadêmico se oferecem à apropriação privada e ao desenvolvimento econômico das empresas. Ressaltam os autores que, com esses interesses econômicos, proliferam em universidades públicas e privadas organismos de gestão de atividades diversas que buscam a captação de recursos e a intermediação com corporações externas, como cursos de extensão dirigidos à capacitação de técnicos em contextos específicos, criação de patentes, desenvolvimento de pesquisas, processos e produtos de inovação.

A segunda expressão a destacar, que Burton Clark (1998) cunhou e tornou mundialmente conhecida, é "universidade empreendedora". Diante das dificuldades do financiamento público e do crescimento das demandas externas relacionadas com a economia, a universidade melhor poderia gerir seu destino sustentando-se mediante recursos captados em diferentes fontes e, mais importante ainda, governando-se à maneira das empresas.

Seguir a lógica administrativa empresarial inclui, entre outras coisas, aceitar a ideia da comercialização do saber, identificar com clareza os núcleos centrais das oportunidades de desenvolvimento, ter sempre no horizonte das ações a busca da eficácia social e da utilidade profissional e selecionar as áreas a que dedicar-se prioritariamente. Nesse modelo de universidade têm relevo as estruturas de sustentação e desenvolvimento da inovação, como os escritórios de transferência de tecnologia, os contratos com empresas, as organiza- 
ções curriculares mais aderentes às demandas das corporações comerciais, a capacitação técnica para ocupação de postos no tecido produtivo.

A economia mundialmente interligada e interdependente amplia e diversifica os pontos de produção, distribuição e consumo. Por isso, o conhecimento não é mais propriedade e função somente de elites. A democratização do conhecimento expande a liberdade nos processos de produção e requer controle mais rígido relativamente ao produto. Estados, com instrumentos rígidos, e sociedade, um pouco difusamente, passaram a exigir do produto final (no caso a formação e o conhecimento) um sentido de utilidade e eficácia social e profissional, bem como responsabilidade pública e prestação de contas dos produtores (professores, cientistas e profissionais em geral). Como tendência geral, estão tendo mais êxito na sociedade da economia globalizada aquelas instituições que mais eficazmente aderem às demandas externas das empresas, dos setores do trabalho, dos governos nacionais e das autoridades políticas e econômicas supranacionais.

Quanto mais as instituições educativas se empenham em atender as demandas do mundo exterior, notadamente as forças do mercado e da política, mais abdicam de sua autonomia na determinação de seus objetivos e na seleção dos meios de os produzir. Correlatamente, cresce o poder da economia globalizada na imposição de modelos de formação e aumenta o controle do Estado sobre os produtos finais. Isso explica, em grande parte, a centralidade que a acreditação, a qualidade e a accountability vêm progressivamente adquirindo. O Estado aumenta seu poder de supervisão, avaliação e regulação, permitindo mais liberdade de processo às IES (gestão, modelos organizacionais, meios) e controlando os produtos mediante indicadores de performatividade, produtividade, análise de relação custo-benefício, desempenho estudantil etc.

\section{ASPECTOS DA TRANSIÇÃO: NOVAS ATRIBUIÇÕES E COMPETÊNCIAS DA UUNIVERSIDADE}

A universidade atual está dividindo com outros espaços geográficos a sua tradicional característica de território intelectual institucionalizado. Semelhantemente ao que ocorre amplamente nas empresas, também alguns cursos e alguns laboratórios de pesquisa se estabelecem em países e regiões diferentes do território e da instituição sede. A transnacionalização em muitos casos se dá mediante atividades que não requerem infraestrutura física de edifícios, nem mesmo a co-presença de profissionais e pesquisadores. A translação geográfica bem como a desmaterialização das atividades intelectuais de ensino, 
pesquisa e inovação têm sua razão de ser na busca de mais competitividade, mais lucros e menores custos de produção. Um exemplo espetacular desse fenômeno pode-se encontrar no grande esforço da China para se tornar competitiva na economia global. Segundo relatórios da ONU (2005) e da National Science Fondation (2010), a China, saindo do zero em 1995, uma década depois (2006) passou a ter setecentos laboratórios de pesquisa de multinacionais estrangeiras (BUCCHI, 2010, p. 181).

O desenvolvimento da ciência no século XX e, sobretudo, desde a Segunda Guerra Mundial apresenta taxas de crescimento exponencial sem paralelo com qualquer outro setor de atividade humana. Esse século assistiu à passagem do que se costuma chamar de little science, isto é a ciência feita por poucos investigadores, em ambientes limitados e sem grande amplitude social e econômica, para a big science, de enormes dimensões e forte conexão com a indústria capitalista. Embora não de forma absoluta e exclusiva, a grande ciência tem inegáveis vínculos com a industrialização, o que constitui também um fator importante de seu espetacular crescimento e de sua centralidade no desenvolvimento do mundo capitalista. Segundo se estima, na atividade de investigação científica e de desenvolvimento tecnológico empenham-se atualmente cerca de cinco milhões e setecentos mil pesquisadores e por volta de um bilhão e cem milhões de dólares (NATIONAL SCIENCE FOUNDATION, 2010; OCDE, 2009 apud BUCCHI, 2010, p. 20).

Outros aspectos importantes, que guardam estreita relação com o crescimento exponencial da ciência, são a diminuição dos tempos de aplicação e a voraz obsolescência das publicações, especialmente na física e ciências biomédicas, disciplinas centrais da big science. Brunner, em texto publicado em 2003, com base em estudos de Rosovsky, Madison, Van Dijk, Salmi, Clark e outros, mostra a velocidade das transformações no mundo do conhecimento. Os números que se seguem já estão desatualizados, pois foram recolhidos há cerca de uma década e meia. Seguem alguns dados selecionados por Brunner: as revistas científicas passaram de 10.000 em 1.900 para mais de 100.000; surgem cerca de 200.000 novos teoremas, anualmente; o número de substâncias químicas conhecidas em 1.978 era de 360.000 e passaram a 1.700.000; a cada 2 anos, são publicados mais de 1.000.000 de artigos em revistas de química; um centro de genômica pode (2003) determinar 1.000 .000 de bases por dia, enquanto em 1.977 levava uma semana para determinar a sequência de 500 bases; surgem 5 livros por dia na área de administração de negócios. E conclui a respeito dessa impressionante explosão e velocidade das transformações epistêmicas: 
Calcula-se que o conhecimento (de base disciplinar, publicado e registrado internacionalmente) havia demorado 1.750 anos para duplicar-se pela primeira vez, contado a partir da era cristã, para depois dobrar seu volume, sucessivamente, em 150 anos, 50 anos e agora a cada 5 anos, estimando-se que até o ano 2.020 se duplicará a cada 73 dias (BRUNNER, 2003, p. 81).

Ao dividir com outros espaços os lugares da produção e ao tornar-se mais difusa a aquisição dos conhecimentos, a universidade perde alguns privilégios tradicionais relativamente ao conhecimento e à formação e ganha outras novas atribuições e competências, por força das determinações da globalização. Esse jogo não é rigidamente bipolar. Em muitos casos, são mais presentes as características híbridas, que supõem a convivência dos dois modos de existência numa mesma instituição e num sistema: elementos da tradição universitária imbricados com as novas tendências e realidades.

Essas transformações qualitativas e quantitativas que marcam as contradições entre um modo de produção tradicionalmente mais restrito e um outro mais aberto e diluído resultam de diversos fatores, como o aumento da escolarização, a democratização dos recursos midiáticos e consequente ampliação das potencialidades da comunicação e da informação, a disseminação da cultura tecnológica etc. As transformações na cadeia da produção e distribuição do conhecimento se imbricam com os processos de mútua interferência das mudanças socioculturais, políticas e econômicas.

De modo especial, as tecnologias da comunicação incidiram intensiva e extensivamente nos modos de produção e de socialização dos conhecimentos. Elas permitiram a desmaterialização de lugares físicos que marcavam rigidamente os territórios intelectuais, potencializaram a ruptura de espaços temporais e a superação da demarcação de fronteiras entre países, por meio da criação de redes de produtores-consumidores de conhecimentos e da expansão cada vez mais ampliada das possibilidades de acesso propiciadas pelos meios informáticos.

Se por um lado a universidade perde em boa parte sua condição monopolista da produção científica e tecnológica, por outro progressivamente vai adquirindo novas funções no mundo globalizado. Ela tem sido central para o fortalecimento e expansão da economia capitalista global do conhecimento e da informação, e, em outra perspectiva, para os intentos, ou sonhos, de construção da sociedade do conhecimento.

Embora não seja mais a fonte e o ancoradouro exclusivos, a universidade vem se transformando em ponto de ligação e comunicação dos diversos conhe- 
cimentos que se produzem em diferentes âmbitos. Vem se constituindo como o lugar privilegiado da interconectividade dos saberes (MOSCATI, 2010, p. 155), graças às suas prerrogativas de operar em várias dimensões distintas do conhecimento: a investigação, a inovação, o ensino, a formação cidadã e profissional, a crítica intelectual. A universidade tem condições privilegiadas para pôr em discussão crítica a tendência de superar as fronteiras disciplinares e os limites entre ciência básica e aplicada. Disciplinas antes desligadas e fechadas em seus próprios confins tendem a se unir e constituir uma nova área de conhecimentos e de aplicação tecnológica. Nessa linha surgem expressões tais como tecnociência, aludindo a proximidade crescente da ciência com os contextos de aplicação, e nexos interdisciplinares como em bioinformática, cibernética, bioética, biotecnologia etc.

Diferentemente de outras instâncias contemporâneas, a universidade continua sendo uma instituição capaz de reorganizar os conhecimentos em forma de disciplinas e de produzir conhecimentos sobre os conhecimentos. Isso é importante não só para organizar as aprendizagens, mas, também, para alavancar o desenvolvimento e abrir novas fronteiras dos conhecimentos. Os conhecimentos particulares e as questões concretas não podem ser barreiras impeditivas do dimensionamento universal, dos enfoques totalizantes e complexos a respeito dos macroproblemas globais.

Quanto mais eficazmente cumpre essas funções, quanto mais consegue construir a unidade dos diferentes saberes com fundamentação científica e acuidade crítica, mais a universidade se fortalece como instituição social encarregada de formar as pessoas para compreenderem a complexidade do mundo em que vivem. A universidade ainda é a instituição com mais condições estruturais e humanas para fazer a crítica da sociedade, prever cenários de possibilidades, interrogar sobre os sentidos dos processos sociais e contribuir para a construção de uma real sociedade do conhecimento, para além da economia do conhecimento.

Essas funções, que nos contextos complexos da contemporaneidade revestem de novos sentidos algumas velhas atribuições, potencializam as contradições que a universidade enfrenta entre os valores internos e externos, a capacitação para altas profissões especializadas e a educação permanente, a formação da consciência crítica e o fortalecimento da competitividade individual. Os Estados, mais precisamente os governos, têm fortes influências sobre a educação superior e ao mesmo tempo precisam administrar as contradições produzidas por diferentes atores dos âmbitos nacionais e internacionais. 


\section{UNIVERSIDADE NA SOCIEDADE DO CONHECIMENTO: PROJETO A CONSTRUIR}

Com relação aos valores universitários, entre uma economia do conhecimento e uma sociedade do conhecimento há distinções essenciais. Embora haja entre ambas pontos de imbricação, pode-se estabelecer também alguns importantes polos de contradição. As diferenças essenciais dizem respeito à concepção a respeito dos significados e dos papéis do conhecimento no mundo, o que remete à questão primordial das finalidades essenciais da universidade. Por sua vez, as finalidades da universidade se ancoram numa concepção de sociedade e no princípio moral que atribui à educação, por meio da construção do conhecimento, a responsabilidade de contribuir para a melhoria dos processos de construção da humanidade.

Como pontuado anteriormente, a economia do conhecimento valoriza o "capitalismo acadêmico" e a "universidade empreendedora". Seu objetivo declarado é promover o desenvolvimento e o progresso, mas, embora aluda a um indefinido benefício social, acaba fortalecendo a ideologia do individualismo possessivo, da rivalidade competitiva e da exclusão dos mais fracos. A sociedade do conhecimento, ainda por construir-se, tem como referência as dimensões e os valores sociais e públicos. Aquela promove o desenvolvimento e o progresso, mas fortalecendo a ideologia do individualismo possessivo, da rivalidade competitiva e da exclusão dos mais fracos. $\mathrm{Na}$ sociedade do conhecimento, idealmente, a educação e o conhecimento seriam elementos fundamentais do bem comum e da elevação geral da condição humana.

Dado seu caráter de universalidade no projeto histórico de construção da humanidade, a universidade tem papel central no processo de edificação da sociedade do conhecimento. Para tanto, ela não pode negar sua natureza essencialmente pública, isto é, concernida à elevação de toda a sociedade humana. Nessa perspectiva, só é digna de nomear-se universidade a instituição que produz e dissemina o conhecimento como direito social e bem público, isto é, como algo essencial e imprescindível à formação de sujeitos capazes de participar criativa e criticamente da sociedade. Em contrapartida, não se poderia considerar universidade uma organização educacional estritamente de caráter mercantil. Universidade e comércio educacional são expressões que se negam e se repelem mutuamente. Universidade se baseia no princípio da solidariedade, ou seja, do patrimônio comum e do bem-estar geral. Negócio cultiva a rivalidade, a posse individual e os benefícios privados. Universidade empresarial é, então, uma contradição em termos. 
A sociedade do conhecimento, democrática e justa, é ainda o sonho e o projeto de uma humanidade culta e igualitária. Em uma verdadeira sociedade do conhecimento, o complexo de ciência, tecnologia, inovação, redes digitalizadas e os processos educacionais formais e informais seriam os motores da elevação da qualidade da vida social de toda a população, assegurados aí os valores da democracia, da equidade e dos demais fundamentos da boa e justa convivência humana.

O conhecimento não seria propriedade privada de minorias, e sim um bem social e direito de todos, para o benefício geral da população. Isso exigiria a construção de uma nova ecologia da produção intelectual e das aprendizagens, isto é, uma democracia cognitiva relativamente à produção, distribuição e usos sociais do conhecimento. A ciência e a tecnologia não seriam o motor de um progresso que produz unidimensionalmente riquezas anulando a subjetividade e deteriorando as bases biológicas e as condições de equidade e dignidade da convivência humana.

As instituições universitárias precisam aperfeiçoar seus processos de inovação epistêmica ajustados às novas condições de produção de conhecimento. O novo modo de produção de conhecimento, chamado de Modo 2 por M. Gibbons et al. (1997, p. 7 apud DIDRIKSSON, 2012, p. 78), se caracteriza pela superação da estrutura disciplinar. É transdisciplinar, supõe a estreita interação entre muitos atores no processo de construção de conhecimento e tende a ser mais reflexivo e socialmente responsável.

Num modelo aberto, solidário e sem a ditadura dos tomadores de decisão a serviço da big science, vários atores participam da produção do conhecimento, em equipes transdisciplinares que agregam pesquisadores de distintos percursos formativos, de diferentes nacionalidades, mobilizando várias instituições acadêmicas em conexão com uma série de outras não-universitárias, redes sociais, grupos de interesses etc. Além da ruptura de fronteiras disciplinares, é desejável que se ampliem os intercâmbios de experiências e resultados entre pesquisadores que trabalham em diversos pontos do mundo (invisible colleges).

Esse almejado e crescente modo de produção de uma sonhada democrática sociedade do conhecimento supõe a interação de diversos atores heterogêneos em relação de colaboração. Disso resulta um certo redirecionamento dos papéis e das relações da universidade no contexto da sociedade. A instituição universitária se infiltra mais na sociedade e, em contrapartida, elementos da sociedade participam da vida interna dos campi, de suas instâncias de decisão, de suas salas de aula e de seus laboratórios e, sobretudo, de seus contextos e de suas relações informacionais. 
A sociedade global e democrática do conhecimento é uma utopia que requer uma educação ampla, participativa, contínua e plural, não orientada exclusivamente à ocupação de postos de trabalho e às demandas da economia, mas com muita ênfase na formação da consciência social, da compreensão do mundo em vertiginosa transformação, do respeito à diversidade, da cooperação criativa, da capacidade de construir um futuro mais solidário e igualitário.

\section{Ideias inconclusas, para continuar o debate}

A sociedade global do conhecimento é uma utopia que requer uma educação ampla, participativa, contínua e plural, não orientada exclusivamente à ocupação de postos de trabalho, mas com muita ênfase na formação da consciência social e da compreensão das culturas, da cooperação criativa e da expansão dos limites individuais como centro de ação e de direcionamento da própria vida.

A torre de Babel contemporânea é feita da proliferação desenfreada da superprodução de informações. Sem controle do rigor científico e ético, fragmentadas e descontínuas, a grande maioria das informações desconexas e fracionadas não contribui para a compreensão da realidade humana, para o enriquecimento da cultura e para a formação intelectual consistente e crítica da população. A informação fragmentada e autofágica não se faz conhecimento. O saber que reduz a verdade à utilidade não se transforma em sabedoria.

As relações de mútua implicação entre o econômico e o simbólico (cultura, conhecimentos, ideologias, valores) determinam hierarquias profissionais e sociais que constituem a distribuição de poderes na sociedade. Portanto, a educação tem um papel de grande importância na conformação dos tipos de sociedade e na configuração dos espaços sociais. Não se pode negar que as escolas de todos os níveis, inclusive a universidade, também têm contribuído para o enraizamento da ideologia do lucro e do individualismo possessivo, e não propriamente para o bem-estar geral da população.

A matéria básica da educação é o conhecimento, mas ainda é necessário agregar algo mais. É fundamental que o conhecimento seja concebido e praticado como bem público e social, ou seja, produzido e transmitido com a finalidade principal de contribuir para o desenvolvimento integral das pessoas e beneficiar o conjunto da sociedade, e não meramente se instrumentalize como artífice do empoderamento individual. Todos têm o direito de aprender, nos tempos adequados e segundo as respectivas potencialidades, os conteúdos formativos que dão substância a uma vida digna, socialmente justa e que conferem legitimidade à democracia. 
Não se constrói uma sociedade democrática, econômica e culturalmente evoluída, sem justiça social e sem uma ampla participação da população dotada de conhecimentos e valores consistentes da cidadania pública. Toda exclusão, e particularmente a educacional, gera mais assimetrias e injustiças sociais, mais atrasos econômicos e culturais e, consequentemente, mais violência, inseguranças e pobreza.

A democratização da educação e do conhecimento é parte essencial da democratização da sociedade. Entretanto, o grande movimento mundial que hoje ocorre pela universalização do acesso à educação guarda muito pouco do sentido das bandeiras da justiça social e da equidade de antes dos anos de 1980 e muito mais dos intentos e dos requerimentos de competitividade da globalização neoliberal. A inclusão educativa é uma questão central da justiça social e, portanto, condição da democracia. Mas a inclusão educativa deve propiciar um outro tipo de educação que não seja mera adesão à agenda global da hegemonia neoliberal. Isso requer retomar o significado essencial dos fins da educação: a formação integral - científica, técnica, profissional, intelectual, cultural, ética, política, social - como processo de construção de sujeitos históricos.

As instituições educativas têm grande potencial para contribuir significativamente com os projetos de democratização da sociedade na medida em que cumpram a responsabilidade social de ampliar e fundamentar a participação civil mais culta e responsável. Ciência e tecnologia têm hoje grandes possibilidades de impulsionar transformações sociais e desenvolvimentos econômicos e culturais à medida que contribuam com os processos de superação de agudos problemas de pobreza, violência, injustiça e desigualdade.

Ampliaram-se as demandas, construíram-se magníficos instrumentos, surgiram novos desafios e possibilidades, nestes tempos de muito desassossego e incomparável capacidade de criação. A Universidade dispõe, atualmente, de um complexo patrimônio de instrumentos e conhecimentos incomensuravelmente maior e mais sofisticado do que reunia em qualquer outro momento de sua história. Os novos modos de produção, circulação e distribuição dos conhecimentos espetacularmente potencializados pelos meios cibernéticos se tornaram acessíveis a grandes massas da população mundial. Mas o conhecimento não se perca pela quantidade, pelo avanço técnico desprovido do ético, pelo desvio de sua responsabilidade essencial relativamente ao processo civilizatório.

Conhecimento é matéria de formação humana. Portanto, há de ter forte significado civilizador. A Universidade é da sociedade humana, não restrita- 
mente do mercado autointeressado. Pelos conhecimentos, valores e práticas democráticas, sua missão histórica é formar integralmente as pessoas e, assim, contribuir para a consolidação e elevação do processo jamais acabado de construção da humanidade. Sem valor público e social, uma universidade não é universidade.

\section{REFERÊNCIAS}

BECK, Ulrich. Qué es la globalización. Falacias del globalismo, respuestas a la globalización. Buenos Aires: Paidós, 2008.

BECK, Ulrich. Sociedade de risco. Rumo a uma outra modernidade. São Paulo: Editora 34, 2010.

BRUNNER, José Joaquín. Aseguramiento de la calidad y nuevas demandas sobre educación superior en América Latina. In: EDUCACIÓN Superior, calidad y acreditación. Bogotá: CNA, 2003.

BUCCHI, Massimiano. Scienza e società. Introduzione alla sociologia della scienza. Nuova edizione riveduta e aggiornata. Milano: Raffaello Cortina Editore, 2010.

CLARK, Burton. Creating entrepreneurial universities. Organizational Pathways of Transformation. Oxford: IAU Press by Pergamon, 1998.

DIDRIKSSON, Axel. La autonomía universitaria en las economías del conocimiento. In: ROSARIO MUÑOZ, Víctor Manuel; MARUM ESPINOSA, Elia; ALVARADO NANDO (Orgs.). La autonomía universitaria a debate. Una visión desde América Latina. Guadalajara: Universidad de Guadalajara, 2010.

DIDRIKSSON, Axel. Universidad y bien público en la perspectiva de una sociedad democrática del conocimiento. In: FUENTE, Juan Ramón de la; DIDRIKSSON, Axel (Orgs.). Universidad, responsabilidad social y bien público. El debate desde América Latina. Guadalajara: Universidad de Guadalajara, 2012.

GIBBONS, Michael et al. La nueva producción del conocimiento, la dinámica de la ciencia y la investigación en las sociedades contemporáneas. Barcelona: Ediciones Pomares-Corredor, 1997. 
MORROW, Raymond A.; TORRES, Carlos Alberto. Estado, globalização e políticas educacionais. In: BURBULES, Nicholas; TORRES, Carlos Alberto (Orgs.). Globalização e educação: perspectivas críticas. Porto Alegre: Artmed, 2004.

HOBSBAWUM, Eric. Tempos fraturados. Cultura e sociedade no Século XX. São Paulo: Cia das Letras, 2013.

MOSCATI, Roberto. Nuove funzioni dell'Università? La ridefinizione delle finalità dell' 'istruzione superiore nella società contemporânea. In: MOSCATI, Roberto (Org.). Comme e perché cambiano la Università in Italia e in Europa. Napoli: Liguori Editore, 2010.

ROIG IBAÑEZ, José. La educación ante un nuevo orden mundial. Madrid-Buenos Aires-México: Ediciones Díaz de Santos, 2006.

SLAUGHTER, Sheila; LESLIE, Larry. Academic capitalism: politics, policies and the entrepreneurial university. Baltimore: The Johns Hopkins University Press, 1997.

ZIMAN, J. La nuova scienza. Bari: Dedalo, 2002. 